\title{
Neuropsychological Evaluation of Children With Intracranial Tumors: Impact of Treatment Modalities
}

\author{
A. García-Pérez, MD, L. Sierrasesumaga, MD, J. Narbona-García, MD, \\ F. Calvo-Manuel, MD, and M. Aguirre-Ventalló, MD
}

From the Child Neurology Service (A.G.-P., J.N.-G.), Pediatric Oncology Service (L.S.), Radiotherapy Service (F.C.-M.), and Department of Psychiatry and Medical Psychology (M.A.-V.), Clínica Universitaria de Navarra, Pamplona, Spain.

\begin{abstract}
Antineoplastic treatment has a deleterious effect on intellectual functions, which is mainly attributable to radiotherapy. With the object of determining the neuropsychological disturbances associated with brain irradiation in the child, and to try to differentiate them from the effects caused by the other types of treatment (surgical and chemotherapy) as well as from the effects of the tumor itself, a cross-sectional study was carried out in 25 survivors of medial edge intracranial tumors. In order to monitor the effect of systemic chemotherapy on the cognitive functions, and the effect of prolonged absence from school, two control groups were formed, one made up of subjects treated with chemotherapy for extracranial tumors, and the other of patients with nonmalignant chronic disease. Neuropsychological functions were measured using the Spanish version of the Wechsler scale, as well as the following tests: SpreenBenton, ITPA and TALE scales, Yuste Memory Test, Thurstone Attention Test, and the Rey Complex Figure.

In addition to a progressive decline found in the full scale intelligence quotient in children irradiated for intracranial tumors, variance analysis showed that these patients deteriorate mainly in visual attention and memory, but also significantly in verbal fluency and in the Performance Intelligence Quotient and all its subtests, when compared to the control groups. Visual attention and the Wechsler Picture Arrangement and Block Designs, were the tests whose decline correlated with the total radiation administered. The article relates this specific neuropsychological injury with the total brain irradiation dose but also with the structures located in the cone-down fields of irradiation to boost regions in the middle edge intracranial content.
\end{abstract}

\section{KEY WORDS}

Intracranial tumors

Cognitive sequelae

Radiotherapy

Chemotherapy

Address reprint requests to A. García-Pérez MD

Unidad de Neurología Infantil, Clínica Universitaria de Navarra.

Apartado de Correos 192, 31080-Pamplona, Spain. 


\section{INTRODUCTION}

At the present time, 1 in every 1,000 adults in the 20-year-old age group is a survivor of childhood cancer [1]. Central nervous system (CNS) tumors take second place after leukemia in the league chart of most frequent malignant conditions suffered in childhood, representing about $20 \%$ of these kinds of illnesses suffered in childhood and adolescence [2]. Radiotherapy (RT) is an important treatment modality used for child intracranial tumors (ICT). This treatment requires the delivery of radical irradiation, usually after surgery, and sometimes followed by whole-brain prophylactic irradiation in order to sterilize any possible ICT extension [3]. Post-mortem examinations reveal that the physiopathological changes produced in the CNS by radiation and chemotherapy (CT) have been described as a necrotizing leukoencephalopathy and a mineralizing microangiopathy [4,5]. The increase in life expectancy brought about by the use of megavoltage radiation has enabled the effect on cognitive functions [6-8]. Given that $70 \%$ of both supra and infratentorial ICT in children are extrahemispherical [9], the posttreatment effect on functional motor handicaps is minimal, whilst the deleterious effect on neurophysiological abilities is far more significant.

With the aim of evaluating the effect of RT on intellectual functions, several studies have been carried out on children with leukemia treated with CNS irradiation. In this type of condition the deterioration of cognitive functions can only be attributed to the iatrogenic effect of the treatment [10-15]. These studies, however, have one principal drawback: all the patients receive the same total dose $(1,800$ or $2,400 \mathrm{cGy})$, which is relatively low compared to that usually used in the treatment of ICT. The aims of the present study on children treated by RT for brain tumors were: a) to verify a deleterious effect on intellectual function produced by RT in these children, attempting to differentiate it from that produced by other types of treatment (surgery and CT) and the tumor itself; and b) to evaluate the possible correlation between the dose of the RT with the degree of neuropsychological deterioration. How this deterioration progresses on time and if the specific intellectual functions affected by the RT vary as a function of the age at which the irradiation is given, has been published separately [16].

\section{MATERIALS AND METHODS}

Between 1980 and 1990, 63 children with ICT were seen in the Clínica Universitaria de Navarra (Service of Pediatric Oncology, Service of Child Neurology, and Service of Radiotherapy). All of them were treated with the conventional doses of RT in a radical therapy attempt. Correlatively 25 of them were taken into account for this study on the basis that they satisfied the following criteria: 1) $\leq 15$ years old when treated; 2) normal psychomotor development up to the commencement of RT; 3) that in every case the tumor was of middle edge and extra-hemispheric, maintaining the integrity of the cerebral hemispheres insofar as the direct action of the tumor and surgery are concerned; 4) that 6 months had elapsed since treatment, allowing a reasonable time for the patient to recover from the effects of surgery and intracranial hypertension, so that only the neuropsychological sequelae of the treatment (CT, RI) would remain. The types and location of the tumors are set out in Table I. 
Two control groups of 25 children each were established (Table II). In order to control the possible effect on cognitive functions produced by CT the first group consisted of patients who had received CT for extracranial tumors (ECT), since some of the patients with ICT had received (CT) in addition to RT. The second group were patients with nonmalignant chronic illness (CHR) in order to control the effects of prolonged absence from school and the emotional disorders caused by serious illness.

The children in these groups were matched with the index group for duration of posttreatment period, age at neuropsychological assessment, and in parental socioeconomic status, graded as (1) primary schooling and low-level employees or manual jobs or (2) secondary/ university degrees and technical/intellectual jobs. The preillness intelligence quotient (IQ) was also similar in the three groups, according to the school intelligence tests carried out before the development of illness. If this information was unavailable, IQ level was estimated by a team of school psychologists on the basis of preillness school grades. The homogeneity of the three groups in the duration of posttreatment period, age at neuropsychological assessment, IQ preillness, and parental sociocultural level was provided statistically (t-test, Mann-Whitney $U$ test, chi-square, and correlation testing).

In order to quantify the different types and doses of the RT received by the children, an RT score was established by a senior radiotherapist for use with statistical analysis. This score was: cGy of whole-brain RT + (cGy of in-volved field RT $x$ the ratio of the brain volume included in the boost). The volume of the geometric figure closest to the brain volume radiated in the boost, according to measures given by X-ray simulation films, divided by whole-brain volume (equivalent to sum of a semisphere plus a semiovoid with the measures given by X-ray simulation films), gave the ratio of the encephalic volume radiated in the boost.

In order to quantify the CT given to the ICT and ECT, a CT score was also established. Since the high doses of methotrexate (MTX) intravenously (i.v.) or the MTX-IT are reported to have a harmful effect on the CNS [4], every $6 \mathrm{~g}$ i.v. of MTX or every conventional administration of MTX-IT was quantified as 1 point. And so was considered as 1 point every dose of CT intra-arterial (i.a.) given directly to the brain (CDDP i.a., BCNU i.a., THIO i.a.). Finally, every whole i.v. administration of other CT agents, since they are not reported to be deletereous for the brain, was only quantified as 0.1 point.

The neuropsychological assessment was performed using the full and specific scores of the Spanish version of the Wechsler scale [17], as well as the following (Table III): Spreen-Benton [18], ITPA [19] and TALE scales [20], Yuste Memory Test [21], Thurstone Attention Test [22], and the Rey Complex Figure [23]. The WISC-R was not used because it had not been standardized on Spanish children at the time of our study. Standardized scores were used where available, and direct test scores were not (Table IV). This was possible because the ages of the three groups had been matched.

Statistical analysis (one-way variance and mean homogeneity analysis) was carried out using parametric and nonparametric statistics, according to whether or not the data were distributed in a normal or uniform manner. Distribution of the data was analyzed by a "normality test" (Statworks). A linear regression test was applied to relate the degree of 
cognitive deterioration (test scores) to the dose of RT administered (RT score). Significance was set at $5 \%$.

\section{RESULTS}

The 25 children with ICT were assessed at time intervals from 6 months to 10 years after treatment. The neuropsychological assessment state of the patient population was as follows: $56 \%$ had full scale intelligence quotient (FSIQ) greater than $90 ; 28 \%$ had FSIQ level between 70 and 90; and 16\% had FSIQ lower than 70.

Comparing preillness IQ and the IQ at our assessment, the decline in FSIQ level was from a mean of 110.2 to a 92, and the drop was as follows: $23 \%$ of the patients experienced a drop of 10 points from their FSIQ score prior to RT; $29.5 \%$ dropped between 10- to 20 points; and $23.5 \%$ lost more than 30 points from their preradiotherapy FSIQ score. In the other groups the mean IQ pre and postillness were in the ECT 107.07 and 107.04, respectively, and in the CHR 108.1 and 106.92.

The FSIQ deteriorated progressively. Among children assessed less than 3 years after RT $31 \%$ showed an FSIQ less than 90 with an average fall of 17.6 points, however, of those assessed at least 3 years after RT, 58\% had an FSIQ of less than 90 and an average fall of 22.3 points (Fig. 1).

Table IV records the means and variation values in the three groups of patients for all the tests applied. The statistical analysis among groups, using parametric and nonparametric tests, shows that the ICT patients present statistically significant differences in FSIQ, Performance IQ (PIQ) and all its subtests (Picture Completion, Picture Arrangements, Object Assembly, Coding, and Block Designs), verbal fluency, visual attention, and verbal and visual memory (Tables V and VI).

To investigate the influence of the dose of RT on the severity of the sequelae, we performed two types of analyses. First, a regression analysis was carried out between the standardized scores of the tests and the RT administered (RT score). Significant regression emerged in the Wechsler performance subtest Block Design $(r=0.45 / \mathrm{P}=$ $0.03)$ and in the Visual Attention test $(\mathrm{r}=0.52 / \mathrm{P}=0.01)$. Second, we divided the group of children into two subgroups according to whether they had an RT score of less than 3,000 (9 children) or greater than 3,000 (16 children), since some regressionscattergrams showed a drop of the test scores environs an RT score of 3,000. Comparison of the two subgroups revealed significant differences for PIQ, for the Wechsler performance subtests Picture Arrangement and Block Design, and for the Visual Attention test (Table VII).

Therefore, it appears that the degree of deterioration in general cognition (Picture Arrangement, and the parameter "Decline" which approaches significance in Table VII), in attention, and in visual-spatial skills (PIQ, Block Design, and Coding which also approaches significance in Table VII), correlates significantly with the total dose of RT. Since an RT score lower than 3,000 corresponds to involved field radiation without whole-brain RT (Table I), it might be assumed that the addition of whole-brain RT to the conventional doses administered adds a significant risk of greater compromise for the specific intellectual functions which tend to be affected. 


\section{DISCUSSION}

The radiation doses used in the treatment of ICT induces a neuropsychological deterioration clearly different from that produced by the action of the tumor itself. This deterioration was not seen in children suffering from CHR nor in children with ECT who had received more intense CT (the mean of CT score for the ICT group was 8.7 and for the ICT group 1.1).

There is some controversy of whether or not, when administered together, CT (mainly MTX) and RT potentiate their effect on normal CNS [4,24]. However, given that only 11 of the children with ICT in this study received neurotoxic drugs with radiation, and this CT was in low dose, and having controlled other variables by the research design, the deterioration observed appears to be largely attributable to RT. Hydrocephaly might also contribute to the deterioration observed. However, Ellenberg et al. [25] have suggested that acute hydrocephaly, in contrast to its chronic form, has not been shown to be an important contributing factor in neuropsychological deterioration since its effects are transitory. Once eliminated, attentional function is restored and bradypsychia disappears.

Children who received RT for middle edge cerebral tumors deteriorated most in visual and verbal memory (Yuste Memory Test and Rey Complex Figure Memory Test), that is, in the ability to identify something as meaningful and to process it in such a way that it can later be remembered; in attention capacity and visual discrimination skills (Visual Attention Test and the Wechsler performance subtests Picture Completion and Coding Tests); in verbal fluency (ITPA Verbal Fluency Test) involving agility in verbalized thinking; and in manual praxias (PIQ and its Object Assembly and Block Design subtests), which measure perception of spatial relations, eye-hand coordination, and anticipatory-sequencing-strategy skills. In summary, children who underwent brain irradiation deteriorated in a number of specific cognitive functions: the most affected was memory, followed by attention capacity, verbal fluency, and sequential processing. Duffner et al. [8,26], Kun and Mulhern [27], Packer et al. [28], Bendersky et al. [29], and Morrow et al. [30] have also found selective deficiencies in memory, attention ability, and visual-spatial organizational skills.

The functional circuit to which attentional and memorial abilities refer is composed of the reticular ascending substance and the limbic-mammillo-thalamic-neostriateorbitomesial connections [31-35]. All these structures are usually located in the conedown fields of the irradiation to boost regions in the middle-edge of the intracranial content. Moreover, this latter circuit influences the selective activation or inhibition of all the convex areas which are directly affected in most cases by the whole-brain RT [36-38]. A reduction in whole-brain radiation would decrease the damage to the cortical and the subcortical white matter of the convexity (in relation to the intramodal and intermodal associative functions: information-processing tasks), improving the information transmission and associative functions. Perhaps dosages similar to those used in meningeal prophylaxis in children with leukemia would be sufficient to sterilize any possible micrometastases of the ICT. It is controversial whether or not such a reduction would be preferable also from the point of view that these lower dosages produce a less significant deterioration in neuropsychological functions [39,40]. Tomita and Mclone [41], Brand et al. [42], and Halberg et al. [43] have shown that the prophylactic radiation dose to the cranial-spinal axis can be decreased without 
jeopardizing control rate and survival in patients, mainly in those low risk patients who have had a total surgical tumor resection and negative myelography and cerebrospinal fluid cytology.

Three-dimensional treatment techniques, and target volumen estimations performed with magnetic resonance imaging (that try to avoid structures related to attentional and memorial functions in the cases where they are not affected by the tumor), will permit more accurate design of treatment programs that will attempt to decrease the long-term sequelae of ICT patients and no compromise of disease control rates.

\section{ACKNOWLEDGMENTS}

We wish to thank Ms. Ruth Breeze and Ms. Karen Sanders for translation of the manuscript.

\section{REFERENCES}

1. Meadows AT, Krejmas NL, Belasco JB: The medical cost of cure: Sequelae in survivors of childhood cancer. Status of curability of childhood cancer. Anderson Hosp Tumor Inst, pp. 263-276, 1980.

2. Young J, Miller R: Incidence of malignant tumors in US children. J Pediatr 86:254258, 1975.

3. Pezeshkpour GH, Henry JM, Armbrustmacher VW: Spinal metastases. A rare mode of presentation of brain tumors. Cancer 54:353-356, 1984.

4. Bleyer WA, Griffin TW: White matter necrosis, mineralizing microangiopathy and intellectual abilities in survivors of childhood leukemia: Associations with central nervous system irradiation and methotrexate therapy. In Gilbert HA, Kagan AR (eds): "Radiation Damage to Nervous System." New York: Raven Press, 1980, pp. 155-174.

5. Packer RJ, Meadows AT, Rourke LB, Goldwein JL, D'Angio G: Long-term sequelae of cancer treatment on the central nervous system in childhood. Med Pediatr Oncol 15:241-253, 1987.

6. Raimondi AT, Tomita T: Advanteges of "total" resection of medulloblastoma and disadvantages of full head post-operative radiation therapy. Child Brain 5:550-551, 1979.

7. Hisrch JF, Reinier D, Czernichow P, Benveniste L, Pierr-Kahn A: Medulloblastoma in childhood. Survival and functional results. Acta Neurochir 48:1-15, 1979.

8. Duffner PK, Cohen ME, Thomas P: Late effects of treatment on the intelligence of children with posterior fossa tumors. Cancer 51:233-237, 1983.

9. Walker AE: Epidemiology of brain tumors: The national survey of intracraneal neoplasms. Neurology 35:219-226, 1985.

10. Copeland DR, Fletcher JM, Pfefferbaum-Levine B, Jaffe N, Ried H, Maior M: Neuropsychological sequelae of childhood cancer in long-term survivors. Pediatrics 75:745-575, 1985.

11. Rowland JH, Glidewell OJ, Sibley RF, Holland JC, Tull R, Berman A, Brecher ML, Harris M, Glicksman AS, Forman E: Effects of different forms of central nervous 
systems prophylaxis on neuropsychological function in childhood leukemia. J Clin Oncol 2:1327-1335,1984.

12. Jannoun L: Are cognitive and educat ional development affected by age at which prophylactic therapy is given in acute lymphoblastic leukemia? Arch Dis Child 58:953-958, 1983.

13. Eiser C: Effects of chronic illness on intellectual development. Arch Dis Child 55:766-770, 1980.

14. Twaddle V, Britton PB, Craft AC, Noble TC, Kernahan J: Intellectual function after treatment for leukemia or solid tumors. Arch Dis Child 58:949-952, 1983.

15. Moss HA, Nannis ED, Poplack DG: The effects of prophylactic treatment of the central nervous system on the intellectual functioning of children with acute lymphocytic leukemia. Am J Med 71:47-52, 1981.

16. García-Pérez A, Narbona-García J, Sierrasesumaga L, AguirreVentalló M, CalvoManuel F: Neuropsychological outcome of children after radiotherapy for intracranial tumours. Dev Med Child Neurol 35:139-148, 1993.

17. Wechsler D: "Escala de Inteligencia de Wechsler para niños (WISC)." The Psychological Corporation. Versión y baremación españolas de T.E.A. Madrid: TEA.

18. Mendilaharsu C: Bateria de pruebas para el estudio del lenguaje del niño, de acuerdo al modelo de Spreen y Benton. In Mendilaharsu CC (ed.): "Estudios Neuropsicológicos." Montevideo: Delta, 1981, pp. 138-162.

19. Von Isser A, Kirk WD: "Prueba Illinois de Habilidades Psicolingüísticas. Adaptación castella del ITPA." University of Arizona, Tucson. Madrid: TEA, 1986.

20. Toro J, Cervera M: "TALE. Test de Análisis de la Lecto-Escritura." Pablo Del Rio. Madrid: TEA, 1980.

21. Yuste Herranz C: "Test de memoria (EGB y BUP), niveles elemental I, II y III." Madrid: TEA, 1982.

22. Thurstone LI, Yela M: "Test de percepción de diferencias (Caras)." Madrid: TEA, 1985.

23. Rey A: "Test de reproducción de una figura compleja. Versión española del manual." Madrid: TEA, 1984.

24. Williams JM, Davis KS: Central nervous system prophylactic treatment for childhood leukemia, neuropsychological outcome studies. Cancer Treat Rev 13:113127, 1986.

25. Ellenberg L, McComb JG, Siegel SE, Stowe S: Factors affecting intellectual outcome in pediatric brain tumor patients. Neurosurgery 21:638-644, 1987.

26. Duffner PK, Cohen ME, Parker MS: Prospective intellectual testing in children with brain tumors. Ann Neurol 23:575-579, 1988.

27. Kun LE, Mulhern RK: Neuropsychologic function in children with brain tumors: II. Serial studies of intellect and time after treatment. Am J Clin Oncol 6:651-656, 1983.

28. Packer RJ, Bruce DA, Atkins TA, Sponso R, Siegel KR, Sutton LN, Schut L: Factors impacting on neurocognitive outcome in long-term survivors of primitive neuroectodermal tumors-medulloblastoma. Ann Neurol 20:396-397, 1986.

29. Bendersky M, Lewis M, Mandelbaum DE, Stanger C: Serial neuropsychological follow-up of a child following craniospinal irradiation. Dev Med Child Neurol 30:808-820, 1988.

30. Morrow J, O'Connor D, Whitman B, Accardo P: CNS irradiation and memory deficit. Dev Med Child Neurol 31:690-692, 1989. 
31. Nauta WJH: Circuitous connections linking cerebral cortex, limbic system and corpus striatum. In Doane BK, Livingston KE (eds): "The Limbic System: Functional Organization and Clinical Disorders." New York: Raven Press, 1986, pp. 43-65.

32. Nauta WJH: A simplified perspective on the basal ganglia and their relation to the limbic system. In Doane BK, Livingston KE (eds): "The Limbic System: Functional Organization and Clinical Disorders." New York: Raven Press, 1986, pp. 67-77.

33. Habib M: "Bases neurologiques des comportements." Paris: Masson, 1989.

34. Mensulam MM: Patterns in behavioral neuroanatomy: Association areas, the limbic system, and hemispheric specialization. In Mensulam MM: (ed): "Principles of Behav oral Neurology." Philadelphia: David Company, 1985.

35. Brouwers P, Riccardi R, Poplack D: Attentional deficits in long-term survivors of childhood acute lymphoblastic leukemia. J Clin Exp Neuropsychol 6:325-336, 1984.

36. Dowell RE, Copeland DR: Cerebral pathology and neuropsychological effects. Differential effects of cranial radiation as a function of age. Am J Pediatr Hematol Oncol 9:68-72, 1987.

37. Cavaness WF: Experimental observations: Delayed necrosis in normal monkey brain. In Gilbert HA, Kagan AR (eds): "Radiation Damage to the Nervous System." New York: Raven Press, 1980, pp. 1-38.

38. Rouke BP: Syndrome of nonverbal learning disabilities: The final common pathway of white-matter disease/dysfunction? Clin Neuropsychol 1:209-234, 1987.

39. Danoff BC, Cowchock S, Marquette C: Assessment of the long term effects of primary radiation therapy for brain tumours in children. Cancer 49:1580-1586, 1982.

40. Fletcher JM, Copeland DR: Neurobehavioral effects of central nervous system prophylactic treatment of cancer in children. J Clin Exp Neuropsychol 10:495-538, 1988.

41. Tomita T, Mclone DG: Medulloblastoma in childhood: Results of radical resection and low-dose neuraxis radiation therapy. J Neurosurg 64:238-242, 1986.

42. Brand WN, Schneider PhA, Tokars RP: Long term results for a pilot study of low dose cranial-spinal irradiation for cerebellar medulloblastoma. Int J Radiat Oncol Biol Phys 13:1641-1645, 1987.

43. Halberg FE, Wara WM, Fippin LF, Edwards MD, Levin VA, Davis RL, Prados $\mathrm{MB}$, Wilson CB: Low-dose craniospinal radiation therapy for medulloblastoma. Int J Radiat Oncol Biol Phys 20:651-655, 1991. 
Table 1. Data Relating to the Patients, Their Tumors, and the RT Received

\begin{tabular}{|c|c|c|c|c|c|c|}
\hline Type of tumor & $\begin{array}{c}\text { Age at } \\
\text { RT } \\
\text { (years) }\end{array}$ & $\begin{array}{c}\text { Interval to } \\
\text { assessment } \\
\text { (months) }\end{array}$ & $\begin{array}{c}\text { Whole-brain } \\
\text { RT } \\
\text { (cGy) }\end{array}$ & $\begin{array}{c}\text { Involved } \\
\text { RT } \\
(\mathbf{c G y})\end{array}$ & Ratio $^{\mathbf{a}}$ & $\begin{array}{c}\text { Score } \\
\text { RT }^{\mathbf{b}}\end{array}$ \\
\hline 1. Medulloblastoma (posterior fossa) & 12 & 6 & 3,000 & 2,000 & 0.27 & 4,396 \\
\hline 2. Medulloblastoma (posterior fossa) & 6 & 7 & 2,600 & 3,000 & 0.20 & 3,768 \\
\hline 3. Pons oligodendroglioma (middle fossa) & 2 & 7 & & 5,000 & 0.51 & 2,527 \\
\hline 4. Astrocytoma IV v. (posterior fossa) & 15 & 7 & 3,000 & 2,000 & 0.15 & 3,752 \\
\hline 5. Thalamic multiform glioma (middle fossa) & 12 & 8 & 3,000 & 2,000 & 0.22 & 4,075 \\
\hline 6. Medulloblastoma (posterior fossa) & 14 & 8 & 3,000 & 2,000 & 0.15 & 3,751 \\
\hline 7. Pineal tumor (middle fossa) & 7 & 14 & 3,000 & 2,000 & 0.13 & 3,671 \\
\hline 8. Optic glioma (anterior fossa) & 13 & 18 & & 6,000 & 0.65 & 3,900 \\
\hline 9. Ependymoma IV v. (posterior fossa) & 15 & 18 & 3,000 & 2,600 & 0.2 & 4,099 \\
\hline 10. Medulloblastoma (posterior fossa) & 14 & 28 & 3,000 & 2,600 & 0.14 & 3,771 \\
\hline 11. Ependymoma IV v. (posterior fossa) & 4 & 33 & 3,000 & 2,000 & 0.17 & 3,837 \\
\hline 12. Optochiasmatic glioma (anterior/middle fossa) & 2 & 35 & & 5,600 & 0.42 & 2,357 \\
\hline 13. Optic glioma (anterior fossa) & 4 & 35 & & 5,400 & 0.17 & 903 \\
\hline 14. Cerebellar astrocytoma (posterior fossa) & 9 & 37 & & 5,800 & 0.35 & 2,030 \\
\hline 15. Ependymoma IV v. (posterior fossa) & 8 & 38 & 2,600 & 2,800 & 0.24 & 3,884 \\
\hline 16. Ependymoma IV v. (posterior fossa) & 2 & 48 & 3,000 & 2,400 & 0.21 & 4,108 \\
\hline 17. Astrocytoma floor III v. (middle fossa) & 9 & 48 & & 6,000 & 0.5 & 3,000 \\
\hline 18. Optic glioma (anterior fossa) & 2 & 56 & & 5,000 & 0.16 & 800 \\
\hline 19. Optic glioma (anterior fossa) & 5 & 60 & & 5,000 & 0.17 & 824 \\
\hline 20. Medulloblastoma (posterior fossa) & 2 & 74 & 3,200 & 1,600 & 0.15 & 3,940 \\
\hline 21. Optochiasmatic astrocytoma (anterior/middle fossa) & 5 & 77 & & 4,839 & 0.47 & 2,278 \\
\hline 22. Brain stem glioma (middle fossa) & 6 & 120 & & 9,360 & 0.7 & 6,595 \\
\hline 23. Medulloblastoma (posterior fossa) & 9 & 120 & 4,000 & 1,200 & 0.11 & 4,580 \\
\hline 24. Medulloblastoma (posterior fossa) & 9 & 120 & 3,000 & 2,000 & 0.18 & 3,900 \\
\hline 25. Cerebellar astrocytoma (posterior fossa) & 15 & 120 & & 4,950 & 0.37 & 1,833 \\
\hline
\end{tabular}

${ }^{b}$ eGy of whole-brain RT + (cGy of involved field RT $x$ the ratio ${ }^{a}$ of brain volume included in the boost). 


\begin{tabular}{|l|l|}
\hline \multicolumn{2}{|c|}{ Table 2. Diseases in the ECT and CHR Groups } \\
\hline 1. Osteoblastic osteosarcoma (left humerus) & $\begin{array}{l}\text { Portal hypertension with bloody esophagic } \\
\text { varices }\end{array}$ \\
\hline 2. Chondroblastic osteosarcoma (right femur) & Crohn's disease \\
\hline 3. Acute lymphoblastic leukemia (no RT given) & $\begin{array}{l}\text { Juvenile rheumatoid arthritis (Still's } \\
\text { disease) }\end{array}$ \\
\hline 4. Osteoblastic osteosarcoma (right humerus) & Disseminated lupus erythematosus \\
\hline 5. Osteoblastic osteosarcoma (right femur) & Crohn's disease \\
\hline 6. Osteoblastic osteosarcoma (left tibia) & $\begin{array}{l}\text { Juvenile rheumatoid arthritis (Still's } \\
\text { disease) }\end{array}$ \\
\hline 7. Osteoblastic osteosarcoma (right tibia) & Polyarticular rheumatoid arthritis \\
\hline 8. Osteoblastic osteosarcoma (right femur) & $\begin{array}{l}\text { Juvenile rheumatoid arthritis (Still's } \\
\text { disease) }\end{array}$ \\
\hline 9. Osteoblastic osteosarcoma (left femur) & $\begin{array}{l}\text { Important scoliosis (operated, long } \\
\text { immobilization) }\end{array}$ \\
\hline 10. Osteoblastic osteosarcoma (right tibia) & $\begin{array}{l}\text { Juvenile rheumatoid arthritis (Still's } \\
\text { disease) }\end{array}$ \\
\hline 11. Abdominal lymphoblastic lymphoma (T cells) & Mucoviscidosis \\
\hline 12. Cervical lymphoblastic lymphoma (T cells) & Polyarticular rheumatoid arthritis \\
\hline 13. Rhabdomyosarcoma (urinary bladder) & Polyarticular rheumatoid arthritis \\
\hline 14. Osteoblastic osteosarcoma (left femur) & $\begin{array}{l}\text { Juvenile rheumatoid arthritis (Still's } \\
\text { disease) }\end{array}$ \\
\hline 15. Ewing sarcoma (left femur) & Turner's syndrome (limbs lengthening) \\
\hline 16. Hodgkin's disease (IV A) & $\begin{array}{l}\text { Fallot tetralogy (several endocarditis, } \\
\text { pacemaker) }\end{array}$ \\
\hline 17. Suprarenal neuroblastoma & Mucoviscidosis \\
\hline 18. Ewing sarcoma (left perone) & Polyarticular rheumatoid arthritis \\
\hline 19. Suprarenal neuroblastoma & Polyarticular rheumatoid arthritis \\
\hline 20. Pheochromocytoma & Primary amyloidosis \\
\hline 21. Ewing sarcoma (fifth rib left) & $\begin{array}{l}\text { Chronic autoimmune hepatopathy (several } \\
\text { biopsies) }\end{array}$ \\
\hline 22. Ewing sarcoma (left tibia) & $\begin{array}{l}\text { Juvenile rheumatoid arthritis (Still's } \\
\text { disease) }\end{array}$ \\
\hline 23. Ewing sarcoma (left tibia) & Chronic granulomatous disease \\
\hline 24. Osteoblastic osteosarcoma (left femur) & $\begin{array}{l}\text { Active chronic hepatitis (aggressive } \\
\text { evolution) }\end{array}$ \\
\hline 25. Wilms' tumor & Crohn's disease \\
\hline
\end{tabular}


Table 3. Neuropsychological Evaluation*

$\begin{array}{ll}\text { General cognition } & \text { FSIQ (WISC) } \\ & \text { Picture Arrangement (WISC) } \\ & \text { Arithmetics (WISC) } \\ & \text { Comprehension (WISC) } \\ \text { VIQ (WISC) } & \text { Vocabulary (WISC) } \\ \text { Language } & \text { Articulation (S. Bentón) } \\ & \text { Sentence Memory (S. Bentón) } \\ & \text { Verbal Fluency (ITPA) } \\ & \text { Similarities (WISC) } \\ & \text { Information (WISC) } \\ & \text { PIQ (WISC) } \\ & \text { Copy Rey Complex Figure Block Designs (WISC) } \\ & \text { Object Assembly (WISC) } \\ & \text { Picture Completion (WISC) } \\ \text { Visual spatial skills } & \text { Coding (WISC) } \\ & \text { Attention Test (Thurstone) } \\ & \text { Digit Span (WISC) } \\ & \text { Metnory Test (Yuste) } \\ & \text { Sequential Visual-Motor Memory (ITPA) } \\ \text { Memory Rey Complex Figure } \\ \text { Arbitrary Writing Errors (TALE) } \\ \text { Natural Writing Errors (TALE) } \\ \text { Reading Test (TALE) } \\ \end{array}$

*This distribution of the tests and subtests permits us to evaluate the different specific functions and construct a neuropsychological profile for each patient. 


\begin{tabular}{|c|c|c|c|c|c|c|}
\hline \multicolumn{7}{|c|}{ Table 4. Descriptive Statistics of the Three Groups } \\
\hline & \multicolumn{2}{|c|}{ ICT } & \multicolumn{2}{|c|}{ ECT } & \multicolumn{2}{|c|}{ CHR } \\
\hline & Mean & SD & Mean & SD & Mean & SD \\
\hline FSIQ & 92.04 & 22.25 & 107.04 & 11.60 & 106.92 & 10.26 \\
\hline VIQ & 97.78 & 14.74 & 102.92 & 11.02 & 103.08 & 12.59 \\
\hline PIQ & 93.48 & 19.03 & 110.13 & 12.41 & 107.4 & 10.63 \\
\hline Picture Arrangement (WISC) & 10 & 3.22 & 11.71 & 2.44 & 12.42 & 1.82 \\
\hline Arithmetic (WISC) & 9.54 & 3.42 & 10.75 & 2.35 & 11.08 & 2.69 \\
\hline Comprehension (WISC) & 9.5 & 2.43 & 10.38 & 2.45 & 10.72 & 2.30 \\
\hline Vocabulary (WISC) & 10.83 & 2.33 & 11.13 & 2.03 & 11.36 & 2.23 \\
\hline Articulation (S. Bentón) $^{\mathrm{a}}$ & $27.78 / 30$ & 2.92 & $28.41 / 30$ & 1.72 & $27.96 / 30$ & 2.25 \\
\hline Sentence Memory (S. Bentón) $^{\mathrm{a}}$ & $22.17 / 26$ & 3.46 & $23.62 / 26$ & 2.65 & $23.92 / 26$ & 2.91 \\
\hline 10. $\quad$ Verbal Fluency (ITPA) $^{\mathrm{a}}$ & 68.35 & 21.22 & 86.67 & 23.12 & 87.16 & 24.39 \\
\hline 11. Similarities (WISC) & 10.52 & 3.09 & 11.92 & 1.98 & 11.48 & 2.14 \\
\hline 12. Information (WISC) & 9.87 & 2.55 & 9.96 & 2.74 & 9.88 & 3.02 \\
\hline 13. Copy Rey Figure ${ }^{b}$ & 41.52 & 19.86 & 52.01 & 12.09 & 51.1 & 9.55 \\
\hline 14. Block Designs (WISC) & 10.41 & 3.17 & 12.46 & 3.70 & 11.76 & 2.40 \\
\hline 15. Object Assembly (WISC) & 9.74 & 3.47 & 12.83 & 3.41 & 11.17 & 2.12 \\
\hline 16. Picture Completion (WISC) & 9.11 & 2.75 & 10.83 & 2.06 & 10.33 & 2.06 \\
\hline 17. Attention Test ${ }^{\mathrm{h}}$ & 38.36 & 14.78 & 54.69 & 10.54 & 53.55 & 7.75 \\
\hline 18. Coding (WISC) & 7.94 & 4.07 & 11.17 & 2.62 & 11.87 & 3.15 \\
\hline 19. Digit Span (WISC) & 9 & 3.27 & 10.14 & 2.63 & 10.63 & 2.43 \\
\hline 20. $\quad$ Memory Test (Yuste) ${ }^{\mathrm{b}}$ & 37.29 & 9.85 & 49.01 & 8.06 & 51.92 & 10.46 \\
\hline $\begin{array}{l}\text { 21. Sequential Visual-Motor } \\
\text { Memory (ITPA) }{ }^{\mathrm{a}}\end{array}$ & $15.78 / 26$ & 5.04 & $18.83 / 26$ & 4.02 & $17.4 / 26$ & 4.66 \\
\hline 22. $\quad$ Memory Rey Figure ${ }^{b}$ & 45.80 & 14.46 & 55.66 & 8.50 & 54.66 & 10.08 \\
\hline 23. $\quad$ Arbitrary Writing Errors $(\mathrm{TALE})^{\mathrm{c}}$ & 5.32 & 5.09 & 5.54 & 4.21 & 6.7 & 4.56 \\
\hline 24. Natural Writing Errors (TALE) ${ }^{\mathrm{c}}$ & 3.5 & 5.31 & 1.42 & 1.99 & 1.7 & 2.51 \\
\hline 25. $\quad$ Reading Test $\left(\right.$ TALE) ${ }^{c}$ & 7.32 & 7.25 & 6.04 & 5.54 & 7.22 & 6.16 \\
\hline \multicolumn{7}{|c|}{$\begin{array}{l}{ }^{a} \text { Direct results. The denominator following oblique denotes maximum score of the test. For } \\
\text { Verbal Fluency direct results are also given (number of words spoken). We could not obtain } \\
\text { normalized results because these tests are not standardized for Spanish population for ages of } \\
\text { our patients. } \\
{ }^{b} \text { Normalized results (mean } 50 \text { SD10). Other tests are WISC subtests (mean } 10 \text { SD3). } \\
{ }^{c} \text { Direct results (number of errors made). }\end{array}$} \\
\hline
\end{tabular}


Table 5. One-Way Variance Analysis Among the Three Groups (Data With Normal Uniform Distribution)

\begin{tabular}{|l|l|l|l|l|}
\hline & $\begin{array}{c}\text { ANOVA } \\
\text { P }\end{array}$ & $\begin{array}{c}\text { ICT vs. ECT } \\
\text { F2,72 }\end{array}$ & $\begin{array}{c}\text { ICT vs. CHR } \\
\text { F2,72 }\end{array}$ & $\begin{array}{c}\text { ECT vs. CHR } \\
\text { F2,72 }\end{array}$ \\
\hline FSIQ & 0.001 & $5.752^{\mathrm{a}}$ & $5.651^{\mathrm{a}}$ & $3.7 \mathrm{E}-4$ \\
\hline VIQ & 0.281 & 0.938 & 1.019 & 0.001 \\
\hline PIQ & 0.0003 & $7.895^{\mathrm{a}}$ & $5.632^{\mathrm{a}}$ & 0.221 \\
\hline Comprehension & 0.213 & 0.748 & 1.505 & 0.127 \\
\hline Vocabulary & 0.703 & 0.108 & 0.353 & 0.071 \\
\hline Articulation & 0.638 & 0.421 & 0.035 & 0.226 \\
\hline Sentence Memory & 0.111 & 1.357 & 2.004 & 0.058 \\
\hline Verbal Fluency & 0.005 & $3.692^{\mathrm{a}}$ & $4.971^{\mathrm{a}}$ & 0.091 \\
\hline Similarities & 0.142 & 1.924 & 0.926 & 0.197 \\
\hline Information & 0.992 & 0.006 & $8.4 \mathrm{E}-5$ & 0.005 \\
\hline Block Designs & 0.077 & 2.569 & 1.149 & 0.306 \\
\hline Picture Completion & 0.038 & $3.241^{\mathrm{a}}$ & 1.617 & 0.285 \\
\hline Memory Test & 0.0001 & $8.894^{\mathrm{a}}$ & $14.14^{\mathrm{a}}$ & 0.573 \\
\hline Sequential Visual-Motor Memory & 0.081 & 2.602 & 0.746 & 0.599 \\
\hline a'Statistical significant differences. & & & \\
\hline
\end{tabular}

Table 6. Nonparametric Variance Analysis Among the Three Groups (Data With Neither Normal Nor Uniform Distribution)

\begin{tabular}{|l|l|l|l|l|}
\hline & Kruskal-Wallis & \multicolumn{3}{|c|}{ U Mann-Whitney } \\
\cline { 2 - 5 } & \multicolumn{1}{|c|}{ P } & $\begin{array}{c}\text { ICT vs. ECT } \\
\text { P }\end{array}$ & $\begin{array}{c}\text { ICT vs. CHR } \\
P\end{array}$ & $\begin{array}{c}\text { ECT vs. CHR } \\
P\end{array}$ \\
\hline Picture Arrangement & $0.007 *$ & $0.032^{*}$ & $0.002^{*}$ & 0.364 \\
\hline Arithmetic & 0.129 & 0.112 & 0.065 & 0.613 \\
\hline Copy Rey Figure & 0.147 & 0.063 & 0.169 & 0.496 \\
\hline Object Assembly & $0.009^{*}$ & $0.004^{*}$ & 0.115 & 0.059 \\
\hline Attention Test & $0.0001 *$ & $0.0002^{*}$ & $0.0002 *$ & 0.836 \\
\hline Coding & $0.001 *$ & $0.003^{*}$ & $0.0008^{*}$ & 0.433 \\
\hline Digit Span & 0.260 & 0.269 & 0.099 & 0.721 \\
\hline Memory Rey Figure & $0.017 *$ & $0.008^{*}$ & $0.022^{*}$ & 0.741 \\
\hline Arbitrary Writing Errors & 0.358 & 0.564 & 0.147 & 0.416 \\
\hline Natural Writing Errors & 0.093 & 0.057 & 0.066 & 0.735 \\
\hline Reading Test & 0.841 & 0.715 & 0.918 & 0.542 \\
\hline$*$ Statistically significant differences. & & & \\
\hline
\end{tabular}


Table 7. Levels of Statistical Significance Obtained From a Comparison of Test Results of Children Irradiated With a Score of RT Greater and Less Than 3,000

\begin{tabular}{|c|c|c|}
\hline & $\mathbf{P}$ & Tests applied \\
\hline FSIQ & 0.2263 & t-test \\
\hline VIQ & 0.5312 & t-test \\
\hline PIQ & $0.0265 *$ & t-test \\
\hline Picture Arrangement & $0.0373 *$ & U-Mann-Whitney \\
\hline Arithmetic & 0.1349 & U-Mann-Whitney \\
\hline Comprehension & 0.3792 & t-test \\
\hline Vocabulary & 0.322 & t-test \\
\hline Articulation & 0.1706 & t-test \\
\hline Sentence Memory & 0.2989 & t-test \\
\hline Verbal Fluency & 0.3738 & t-test \\
\hline Similarities & 0.1687 & t-test \\
\hline Information & 0.8624 & t-test \\
\hline Copy Fey Figure & 0.9228 & U-Mann-Whitney \\
\hline Block Design & $0.0565 *$ & t-test \\
\hline Object Assembly & 0.1118 & U-Mann-Whitney \\
\hline Picture Completion & 0.1077 & t-test \\
\hline Attention Test & $0.0201 *$ & U-Mann-Whitney \\
\hline Coding & 0.0802 & U-Mann-Whitney \\
\hline Digit Span & 0.7039 & U-Mann-Whitney \\
\hline Memory Test & 0.2223 & t-test \\
\hline Sequential Visual-Motor Memory & 0.3625 & t-test \\
\hline Memory Rey Figure & 0.5849 & U-Mann-Whitney \\
\hline Arbitrary Writing Errors & 0.4983 & t-test \\
\hline Natural Writing Errors & 0.5309 & t-test \\
\hline Reading Test & 0.3974 & t-test \\
\hline FSIQ Decline $^{\mathrm{a}}$ & 0.0834 & t-test \\
\hline
\end{tabular}

* Statistically significant differences.

${ }^{a}$ Result obtained by subtracting the preillness and post-RT FSIQ. 


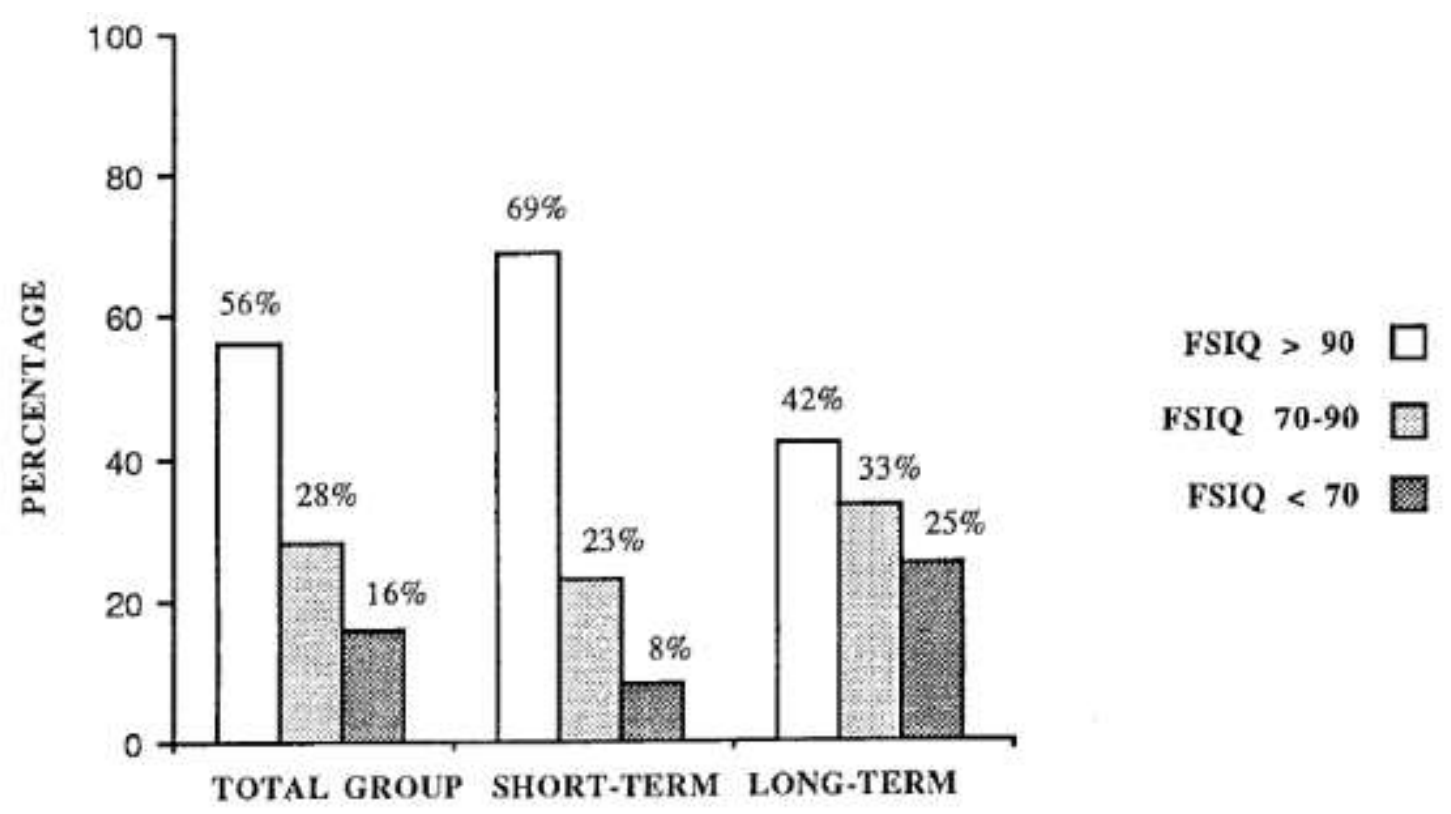

Fig. 1. FSIQ deterioration in children irradiated for ICT. Short-term follow-up: 6 months to 3 years post-RT (13 patients), long-term follow-up: 3 years to 10 years post-RT (12 patients). See Table 1.

Figure 1. FSIQ deterioration in children irradiated for ICT. Short-term follow-up: 6 months to 3 years post-RT (13 patients), long-term follow-up: 3 years to 10 years post-RT (12 patients). See Table I. 